\title{
Correction to: An antibody-free LC-MS/MS method for the quantification of intact insulin-like growth factors 1 and 2 in human plasma
}

\author{
Mark S. Pratt ${ }^{1}$ (D) $\cdot$ Martijn van Faassen ${ }^{1} \cdot$ Noah Remmelts $^{1} \cdot$ Rainer Bischoff $^{2} \cdot$ Ido P. Kema $^{1}$
}

Received: 25 June 2021 / Accepted: 25 June 2021 / Published online: 16 July 2021

(C) Springer-Verlag GmbH Germany, part of Springer Nature 2021

\section{Correction to: Analytical and Bioanalytical Chemistry} https://doi.org/10.1007/s00216-021-03185-y

The authors would like to call the reader's attention to the fact that, unfortunately, there was an oversight regarding the funding information in this manuscript; please find the correct information below:

Funding information

This collaboration project is co-financed by the Ministry of Economic Affairs and Climate Policy by means of the PPPallowance made available by the Top Sector Life Sciences \& Health to stimulate public-private partnerships.

Publisher's note Springer Nature remains neutral with regard to jurisdictional claims in published maps and institutional affiliations.

The online version of the original article can be found at https://doi.org/ 10.1007/s00216-021-03185-y

Ido P. Kema

i.p.kema@umcg.nl

1 Department of Laboratory Medicine, University Medical Center

Groningen, University of Groningen, Hanzeplein 1, 9713, GZ

Groningen, The Netherlands

2 Department of Analytical Biochemistry, Groningen Research Institute of Pharmacy, University of Groningen, Antonius

Deusinglaan 1, 9713, AV Groningen, The Netherlands 